\title{
Nanoimprinted Long-range Surface Plasmon Polariton Waveguide Components
}

Johansen, Dan Mario; Boltasseva, A.; Nielsen, Theodor; Vogler, M.; Grützner, G.; Reuther, F,; Leosson, K.; Kristensen, Anders

Published in:

Proceedings of CLEO/QELS 2006

Link to article, DOI:

10.1109/CLEO.2006.4628961

Publication date:

2006

Document Version

Publisher's PDF, also known as Version of record

Link back to DTU Orbit

Citation (APA):

Johansen, D. M., Boltasseva, A., Nielsen, T., Vogler, M., Grützner, G., Reuther, F., Leosson, K., \& Kristensen, A. (2006). Nanoimprinted Long-range Surface Plasmon Polariton Waveguide Components. In Proceedings of CLEO/QELS 2006 (pp. 1-2). IEEE. https://doi.org/10.1109/CLEO.2006.4628961

\section{General rights}

Copyright and moral rights for the publications made accessible in the public portal are retained by the authors and/or other copyright owners and it is a condition of accessing publications that users recognise and abide by the legal requirements associated with these rights.

- Users may download and print one copy of any publication from the public portal for the purpose of private study or research.

- You may not further distribute the material or use it for any profit-making activity or commercial gain

- You may freely distribute the URL identifying the publication in the public portal 


\title{
Nanoimprinted Long-range Surface Plasmon Polariton Waveguide Components
}

\author{
D. M. Johansen ${ }^{1}$, A. Boltasseva ${ }^{2}$, T. Nielsen ${ }^{1}$, M. Vogler ${ }^{3}$, G. Grützner ${ }^{3}$, F. Reuther ${ }^{3}$, \\ K. Leosson ${ }^{4}$, and A. Kristensen ${ }^{1, *}$ \\ ${ }^{1}$ MIC-Department of Micro and Nanotechnology, Nano.DTU, Technical University of Denmark, DK-2800 Kongens Lyngby, Denmark \\ ${ }^{2}$ COM.DTU, Nano.DTU, Technical University of Denmark, DK-2800 Kongens Lyngby, Denmark \\ ${ }^{3}$ micro resist technology GmbH, Köpenicker Str. 325, D-12555 Berlin, Germany \\ ${ }^{4}$ Lumiscence A/S, Ryttermarken 15, DK-3520 Farum, Denmark \\ "Corresponding author, e-mail: ak@mic.dtu.dk
}

\begin{abstract}
We report on the fabrication by nanoimprint lithography (NIL) and performance of metal stripe waveguides embedded in a polymer, capable of supporting long-range surface plasmon polariton (LRSPP) propagation.

(C)2003 Optical Society of America

OCIS codes: (240.6680) Surface plasmons; (220.4000) Microstructure fabrication
\end{abstract}

In recent years, surface plasmon photonics have received increasing interest [1]. The unique properties of surface plasmon polaritons (SPPs) can be harnessed to improve light extraction from light-emitting diodes, to realize highly surface-sensitive detectors, to surpass the conventional diffraction limit in integrated optics, etc. However, the applicability of surface plasmon waveguides to integrated optics is often limited by high propagation loss caused by absorption in the metal and by difficulties in coupling light in and out of the waveguides. One way to overcome these problems is to use so-called long-range SPP waveguides which consist of an ultra-thin layer of metal embedded in a dielectric material. Such structures have been fabricated previously, using glass-polymer [2] or polymer-polymer sandwiches [3], leading to new device designs compatible with standard optical fibre technology, including devices containing sub-wavelength features patterned with electron-beam lithography [4].

The aim of the present work is to develop a fabrication process for LRSPP waveguides compatible with NIL and wafer bonding. This technique is well suited for mass production of components with nano-scale features and allows the LRSPP waveguide technology to be integrated into more complex device geometries, e.g. including microfluidic channels. As a cladding material, we used mr-I T85-20.0 nanoimprint resist from micro resist technology $\mathrm{GmbH}$. This material has an excellent chemical resistance, low water absorption, and high optical transparency which is compatible with UV lithography and metal deposition [5].

(a) Spincoat mr-l T85

(b) Imprint/planarize

(c) Gold deposition

(d) Lift-off

(e) Thermal bonding
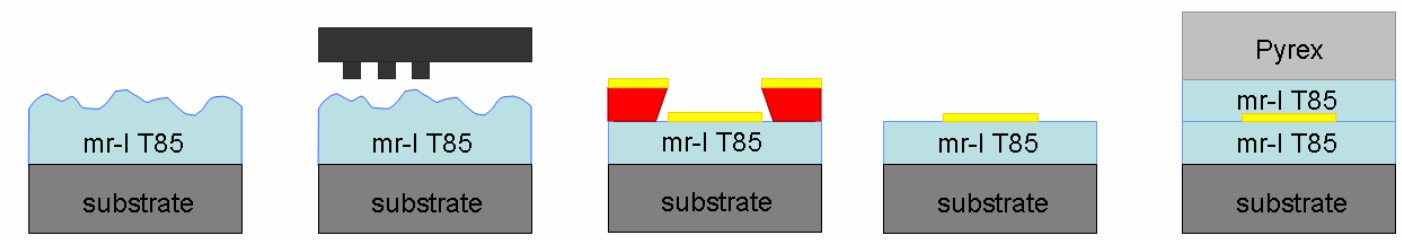

Fig. 1. Outline of the fabrication process. (a) mr-I T85 is spin-coated on a Si wafer. (b)) Planarization/ imprint of mr-I T85 film. (c) UV-lithography defines the waveguide and gold is deposited. (d) Lift-off of the gold film. (e) A mr-I T85 covered Pyrex wafer is bonded on top to embed the waveguide.

Waveguides were fabricated as follows, Figure 1: A silicon wafer is spin-coated with a $20 \mu \mathrm{m}$ thick layer of mrI T85. The surface can be planarized by embossing with a blank silicon wafer in order to reduce scattering loss caused by surface roughness. Photoresist patterning, gold deposition and lift-off were used to define straight waveguides with widths ranging from $3 \mu \mathrm{m}$ to $12 \mu \mathrm{m}$. The top polymer cladding was formed by spin-coating a Pyrex wafer with a similar mr-I T85 layer and the two wafers were then bonded together at $100^{\circ} \mathrm{C}$ and $10 \mathrm{kN}$ in a parallel plate embossing machine. The bonded wafers were diced to different lengths for optical transmission measurements. 


\section{QMI6.pdf}

(a)

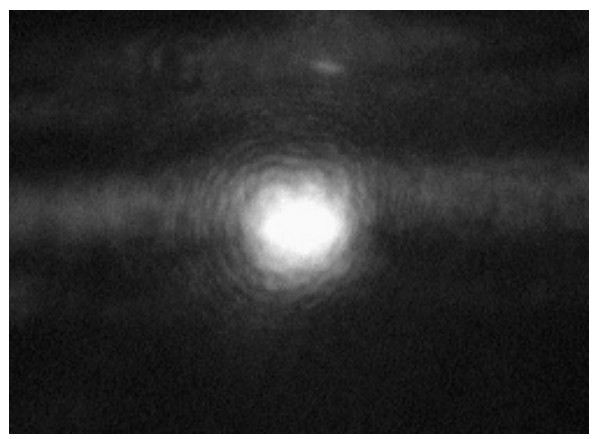

(b)

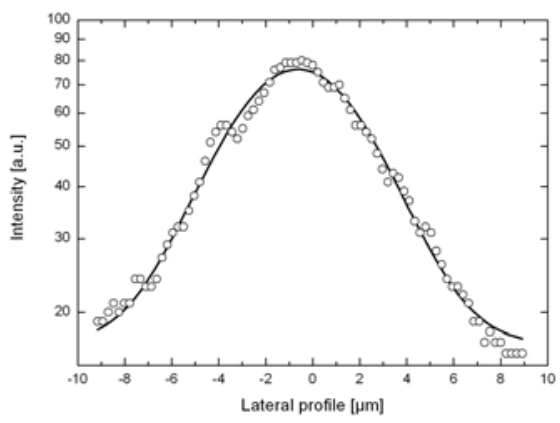

Fig. 2. a) Image of the output facet of an $8 \mu \mathrm{m}$ wide gold stripe waveguide transmitting light at $1550 \mathrm{~nm}$. b) The intensity distribution is well described by a Gaussian mode profile having a mode field diameter of $12.8 \mu \mathrm{m}$

Transmission measurements were carried out by launching light at $1550 \mathrm{~nm}$ wavelength from a laser, through a polarization controller into a polarization-maintaining fibre. The light was coupled directly from the fibre to the waveguides using end-fire coupling of TM polarized light (the metallic stripe waveguide only supports TM polarization). The output facet was imaged onto a Vidicon camera and mode field characteristics were studied. Figure 2a shows a typical picture of a sample facet. For $10 \mathrm{~nm}$ thick, $8 \mu \mathrm{m}$ wide waveguides, the mode field diameter is symmetric and well matched to that of a standard single-mode fibre (Figure 2b). Cut-back measurements indicate that the propagation loss is similar to that reported in waveguides fabricated by other techniques [2,3].

(a)

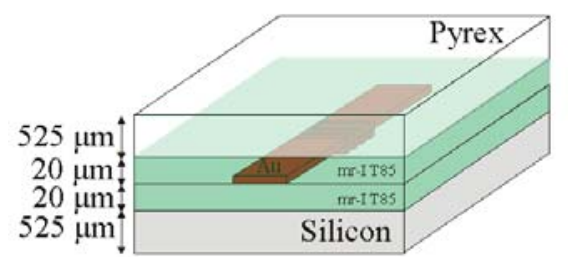

(b)

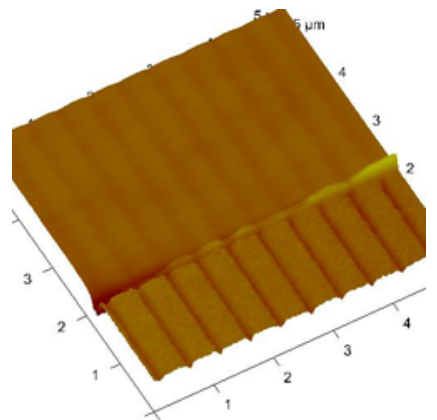

Fig. 3. a) Schematic of a device structure containing an LRSPP waveguide with a reflection grating, fabricated by nanoimprint technology. b) AFM image of the edge of the Au stripe, with the $508 \mathrm{~nm}$ period reflection grating.imprinted in the underlying polymer.

In order to demonstrate the use of nanoimprint technology we also fabricated waveguides with reflection gratings based on small periodic perturbations in the metal film. A silicon stamp was patterned using electron beam lithography and etching. Gratings with a period of $508 \mathrm{~nm}$ and height of $10 \mathrm{~nm}$ were imprinted in the bottom cladding prior to gold deposition, see Figure 3.

[1] W. L. Barnes, A. Dereux, and T. W. Ebbesen, "Surface plasmon subwavelength optics", Nature 424, 824-830 (2003).

[2] R. Charbonneau, N. Lahoud, G. Mattiussi, and P. Berini, "Demonstration of integrated optics elements based on long-ranging surface plasmon polaritons", Optics Express 13, 977-984 (2005).

[3] A. Boltasseva, T. Nikolajsen, K. Leosson, K. Kjaer, M. S. Larsen, and S. I. Bozhevolnyi, "Integrated optical components utilizing long-range surface plasmon polaritons", Journal of Lightwave Technology 23, 413-422 (2005).

[4] S. I. Bozhevolnyi, A. Boltasseva, T. Søndergaard, T. Nikolajsen, and K. Leosson, "Photonic bandgap structures for long-range surface plasmon polaritons", Optics Communications 250, 328-333 (2005).

[5] T. Nielsen, D. Nilsson, F. Bundgaard, P. Shi, P. Szabo, O. Geschke, and A. Kristensen, "Nanoimprint lithography in the cyclic olefin copolymer, Topas, a highly UV-transparent and chemically resistant thermoplast”, J. Vac. Sci. Technol. B 22, 1770-1775 (2004). 